\title{
Retraction Note to: An analysis of population structure and linkage disequilibrium using multilocus data in 187 maize inbred lines
}

\author{
Chuanxiao Xie $\cdot$ Marilyn Warburton • \\ Mingshun Li • Xinhai Li • Muji Xiao • \\ Zhuanfang Hao $\cdot$ Qi Zhao $\cdot$ Shihuang Zhang
}

Published online: 8 March 2011

(C) Springer Science+Business Media B.V. 2011

Retraction Note to: Mol Breeding (2008) 21:407-418

DOI 10.1007/s11032-007-9140-8

This article is retracted because of inappropriate re-use of some of the figures and text by the authors without the necessary permissions.

The online version of the original article can be found under doi:10.1007/s11032-007-9140-8.

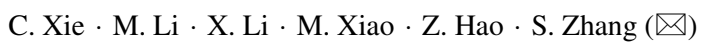
National Key Facility of Crop Gene Resources and Genetic Improvement, Institute of Crop Science, Chinese Academy of Agricultural Sciences, 12 Zhong-guan-cun South St., 100081 Beijing, P.R. China

e-mail: cshzhang2000@yahoo.com.cn; cxxie@caas.net.cn

M. Warburton

Applied Biotechnology Center CIMMYT Apdo, Apdo.

Postal 6-641, Mexico, D.F. 06600, Mexico

Q. Zhao

Life School, Beijing Capital Normal University, Beijing,

P.R. China 